\title{
A toolbox for democratic and participatory methods in education
}

\author{
Gwendolyn Kolfschoten \\ Delft University of Technology, Faculty of Technology Policy and Management, Department of System \\ Engineering, Jaffalaan 5, 2628 BX Delft, The Netherlands \\ E-mail: G.L.Kolfschoten@tudelft.nl
}

\begin{abstract}
With the trends in the use of social software and social media, a more informal and democratic online culture is developing, especially in younger generations. This culture is increasingly conflicting with traditional teaching styles. One of these trends involves the introduction of more democratic and participatory interaction styles in daily activities, online and for larger communities. E-democracy tools and methods could be an important means to facilitate e-democracy in traditional education. However, e-democracy poses a number of challenges, which require careful consideration when implementing a democratic process. One of the disciplines that can offer solutions to these challenges is the facilitation of group and collaboration processes with the use of Group Support Systems. A recent development in this area of research is the use of design patterns to document techniques for collaboration. In this paper we present a set of design patterns for the facilitation of e-democracy, that can be used in traditional education.
\end{abstract}

Keywords: social software, social media, e-democracy, facilitation techniques, design patterns, Group Support Systems, participation.

\section{Introduction}

With the trends in the use of social media, a more informal and democratic online culture is developing, especially in younger generations. A recent report from Nielsen (Nielsen, 2011) shows that in 2010 people spend 22 percent from their online time on social networking sites, in the US users of social networking sites spent an average of 6 hours per month on these sites, and it is expected that these numbers are higher for children and students. Forrester reports that in 2009 the US only 3 percent of people aged 18-24 are inactive on social media, in Europe this is 17 percent (Forrester, 2011). Combined with this trend rises the introduction of more democratic and participatory interaction styles, online and for larger communities. A key indicator of this trend is the use of facebook and other social media to call for revolution in several countries in the Middle East, early 2011.

Democracy is a Greek term (demos, kratos) and means 'ruled by the people'. Democracy has become the leading form of government in our society. In 2006, 122 countries have electoral democracy (Larson, 2006), and this number is increasing.

(C) Baltzer Science Publishers 
Voting and referenda are typical ways in which democracy is implemented. However, trends towards a more direct democracy style are emerging. In a direct democracy, selfmanagement of groups is encouraged, with the 'threat' of policy or legislation when self-management is not effective. Another style of direct democracy is to base decisions on a more thorough consultation of opinions and stakes involved (Clift, 2000). Democratic education can be interpreted in a direct, classical and representative, contemporary model. In the direct model, a more informal participatory learning approach is envisioned in which reflection and critical thinking are encouraged. The representative model is a more traditional hierarchical learning model with a focus on competition (Carr \& Hartnett, 1996; Smith, 2001). Democracy in education can have an effect on pupil's engagement. When pupils decide (what) to learn themselves it can improve motivation. A classic resource on this philosophical perspective is offered in (Dewey, 1916). Critical reflection, and thinking about problems in a multi perspective fashion is a critical skill, not only for citizenship, but in general to develop learning skills and to stimulate professional and social behavior. In this paper we will not discuss the philosophical or psychological considerations of democracy in education, rather it deals with the practical concerns of democracy in larger groups, and how software can be used to introduce and use democracy in traditional education.

In education a variety of decisions and choices can be democratized to stimulate commitment and ownership of the learning process. This offers opportunities for example to set more effective school rules, to make democratic choices in learning topics, and to make decisions on social activities such as e.g. field trips. Also in didactic methods such as problem solving tasks, democratic consensus building techniques can benefit learning, as it supports mutual learning, commitment to learning and exploring different perspectives of a problem (Entin, Sidman, \& Neal Gualtieri, 2009).

Decision making and collaboration in large groups is very complex for students to coordinate by themselves, especially online and in larger groups. Therefore facilitation of the different democratic activities is required. Facilitation of decision making in large groups is a challenge on its own, and mainly requires effective analysis and organization of contributions to create an overview of different perspectives for decision making.

This paper will therefore offer a framework to identify requirements for e-democracy activities. In this framework we will explain how input from large groups or communities can be transformed, using information systems, to a manageable amount of input that can be used in teaching, and to give feedback. Next, it will offer a set of techniques based on the thinkLet concept (Kolfschoten et al., 2006; de Vreede, Briggs, \& Kolfschoten, 2006). ThinkLets are design patterns; scripted best practices, for collaboration. In this paper we present a collection of design patterns that describe e-democracy techniques. We will present these with a set of examples to constitute a toolbox for edemocracy. For the elements of this toolbox we will offer examples of websites where such techniques and/or tools have been implemented to support e-democracy in education contexts. 
In the next section we will give a brief overview of the patterns and challenges in facilitation of large asynchronous distributed groups. Next we will offer a typology of activities in democracy and we will offer an overview of the input from students of pupils needed for each activity. With this background we can distil a set of requirements for the facilitation of e-democracy. We will present these requirements as a set of rules that teachers or educators need to impose on students in the e-democracy process to facilitate inquiry of the information that is needed for the activity. The rules are built according to the design pattern concept, to enable teachers to make predictable, reusable interventions in an e-democracy activity. Furthermore, they will enable easy transition of these e-democracy tools. In Section 4 we will explain the requirements for the e-democracy toolbox. In Section 5 we will explain the thinkLet concept. In Section 6 we will present the e-democracy toolbox. We end with conclusions and directions for future research.

\section{Facilitation to support collaboration and decision making}

Groups might not be able to overcome the challenges of collaboration by themselves (Nunamaker et al., 1997; Schwarz, 1994). Even if groups are able to accomplish their goals, they can often collaborate more efficiently and effectively using collaboration support (Fjermestad \& Hiltz, 2001; Schwarz, 1994). Collaboration support can be offered in different shapes, such as facilitation, training and by offering collaboration tools. Tools for group support range from complex computer systems (groupware), to simple cards and pencils, but neither are very intuitive to use effectively. Therefore, tools are often combined with instruction, training or facilitation (Dennis \& Wixom, 2002). Facilitators intervene in a group process to support the group in achieving their goals (Clawson, Bostrom, \& Anson, 1993; Hayne, 1999; Macaulay, Alabdulkarim, \& Kolfschoten, 2006; de Vreede, Boonstra, \& Niederman, 2002). These interventions can be instructions to contribute a specific type of information (brainstorm solutions for this problem), or they can be more interactive interventions to integrate contributions of different group members (facilitating a discussion to get consensus about a definition).

In order to facilitate e-democracy in education we need to offer tools and guidelines to enable direct contribution to a decision making process, in an online fashion, in a way that constitutes learning and knowledge building. Teachers or education staff could take the role of facilitator, but (older) students could also use more advanced technologies that guide the group though a democratic process. When teachers adopt the facilitation role, there is one key pitfall they must consider. Once a democratic approach is introduced, the students collectively decide the outcome. Ignoring or countering a democratic outcome can lead to protest as it does in politics, which means that once a democratic approach is chosen, the school, teachers and parents will need to take the student's voice serious. We expect the methods proposed here to work with pupils at high school level and in higher education, perhaps also in the last years of primary education. The examples presented are also focused on this age group. 
A specific sub set of tools for collaboration and decision support are Group (Decision) Support Systems. The characteristics of such systems (Bostrom, Watson, \& Kinney, 1992) are that they offer parallel communication tools to gather many viewpoints (Fjermestad \& Hiltz, 2001; de Vreede et al., 2003), that they are anonymous, enabling a feeling of safety, and more open communication (Nunamaker et al., 1997; Wilson \& Jessup, 1995), and that they offer electronic recording and processing of contributions (Bostrom, Watson, \& Kinney, 1992). Because of these characteristics, various advantages of group work, e.g. synergy, mutual stimulation, knowledge sharing etc. can be enforced. These characteristics further support democratic decision making, avoid bias, increase transparency, and encourage equally and fairness. The potential disadvantages of group work such as dominance, groupthink, etc. can be diminished. Because of this, a higher level of productivity and a better quality of results can be achieved (Fjermestad \& Hiltz, 2001; Nunamaker et al., 1997; de Vreede et al., 2003). Collaborative learning using these technologies reports similar advantages (Dillenbourg, 1999; Johnson \& Johnson, 1994), but does not necessarily adhere democratic principles.

An additional trend in use of collaboration support tools emerges from the use of social networks and social media. While collaboration support tools and social media traditionally stem from different disciplines, they are now merging to become more similar. Typically, these media function without facilitation, or with the use of rules and guidance that is embedded in the tools. For instance, Wikipedia has a build-in reviewing system to guard the quality of content. Another example is the ability in online games to vote off players who are rude or don't follow the rules of the game. These types of functionalities in the online collaborative environment take over the role of a facilitator. However, not all facilitation tasks can be automated in this way. Therefore the toolbox for facilitation of e-democracy presented below offers guidelines for teachers to effectively use social media for democratic decision making processes. This toolbox will help to overcome three key types of challenges in democratic decision making:

- Challenges of large groups.

- Challenges of online input.

- Challenges of participation.

\subsection{Challenges of large groups}

Democracy requires a certain group size and representation of 'stakeholders' in order to be meaningful. In order to enable all students to participate, the e-democracy activity needs the capability to handle large amounts of information. In 'one-way communication' this might not be too difficult (voting, survey) but meaningful interactive discussion in large groups is very challenging. Parallel communication as used in GSS recognizes this problem as information overload (Nunamaker et al., 1997). When the input from all participants is visible for others, the input rate can exceed the speed of reading and responding, causing information overload. Therefore we need to structure 
or summarize the input of participants. In e-democracy it is important that summarizing efforts do not become censorship; convergence methods that are proposed in GSS literature such as peer reviewing (Helquist, Kruse, \& Adkins, 2006) and progression of high rated contributions (Faieta, Huberman, \& Verhaeghe, 2006) might not qualify for e-democracy as minority ideas cannot progress. Consequently fair convergence methods are required.

\subsection{Challenges of online communication}

A second challenge is given by the setting in which the interaction takes place. Since people contribute online over a period of time we can classify this setting as distributed asynchronous communication (Mittleman et al., 1999). In this setting facilitation interventions become more challenging (den Hengst et al., 2005; Niederman, Beise, \& Beranek, 1993; Romano et al., 1999). Furthermore, especially consensus building, a key democratic process, is a highly demanding facilitation task (den Hengst \& Adkins, 2007). One of the key challenges in this setting is the lack of non-verbal feedback (body language) for the facilitator (McQuaid et al., 2000; Niederman, Beise, \& Beranek, 1993; Romano et al., 1999). Without this cue it is difficult to assess engagement of the students, and to detect signs of conflict or flaming (Reinig, Briggs, \& Nunamaker, 1998) or to interpret silence (Ter Bush \& Mittleman, 2006). Another challenge is that the communication channel for discussion and for process instructions and non-content related remarks of the students should be separated (McQuaid et al., 2000; Niederman, Beise, \& Beranek, 1993; Romano et al., 1999). When instructions or feedback are mixed with content, they are easily overlooked.

\subsection{Challenges of participation}

A third challenge is the participation of students. The more voluntary nature of social media can infer with learning and as 'online culture' is more informal, compliance to instruction can be less consistent. Students are much more skilled in multi-tasking than older generations (Veen, 2009), but the discipline to divide time between social and learning activities remains important. Addiction to games adds to this challenge. We thus need to ensure that students or pupils participate in the process, by making it engaging and creating a sense of self-responsibility.

\section{Requirements to the toolbox for facilitation of e-democracy}

Democratic decisions are usually made based on a set of alternative proposals, that represent different perspectives to a solution. Teachers or institutions as well as students themselves can suggest proposals, and proposals can the perspective of a group of stakeholders, or they can be individual perspectives. Once proposals are identified, participants should choose among them, and these 'vote' should be aggregated. When the 
information gathered from the students leads directly to decisions based on a majority rule, Astrom names this a quick democracy. When the teacher/school decides based on discussion with students he calls it a strong democracy. A third form, thin democracy is one where accountability of representatives (e.g. student council, class representative) is used to make legitimate decisions (Astrom, 2001). Therefore, the use of social media is focused respectively on decision making (quick), discussion/debate (strong), and informing the students (thin) (Gronlund, 2003).

When we combine these approaches we can create an overview of e-democracy approaches where we combine a method for proposal generation with a method for decision aggregation.

Teacher individual proposals

Teacher converged proposals

Student individual proposals

Student group proposals
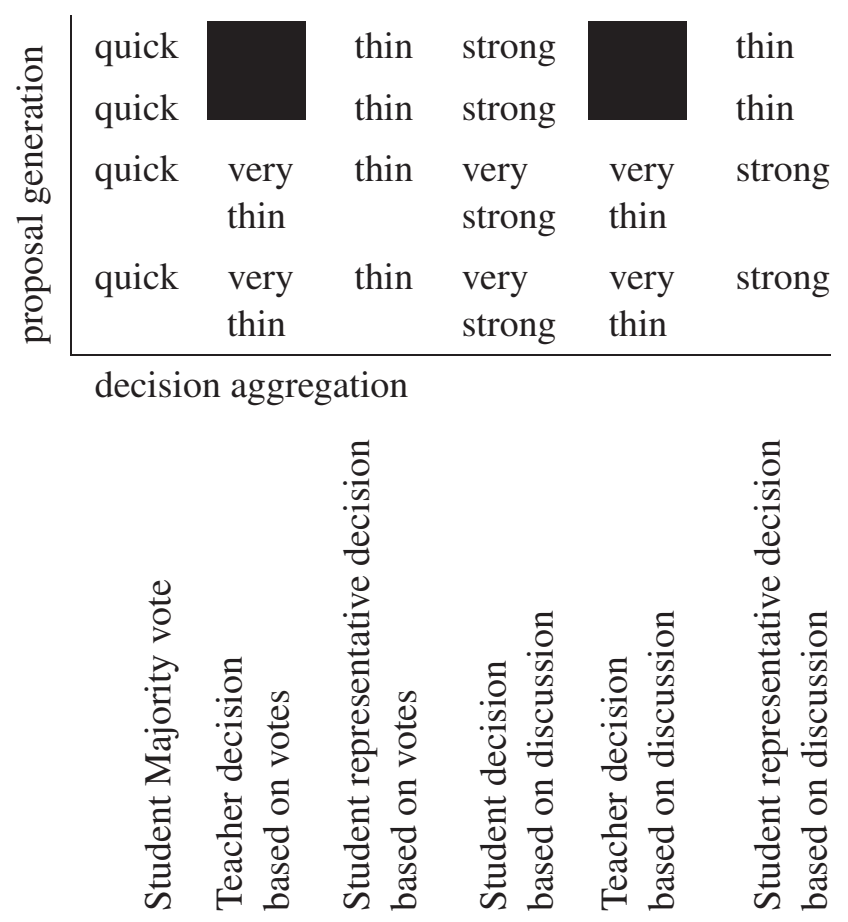

Traditionally quick democracy is used where the public is asked to vote pro or against a proposal, or to indicate their preference for a proposal (select one). In a representative democracy, such preference is not yet a decision, but usually leaders decide to adopt the result of the vote. In education, one can imagine what happens if the students voted by majority to go on a field trip to a zoo, and the school decides to take them to a museum after all. When the students asked to vote more frequently, it becomes highly important to make voting easy, accessible and simple to aggregate. Surveying tools such as surveymonkey or limesurvey can be used for this. 
When a teacher or school wants to make a more informed decision, a thin democracy, it can in addition to a vote, ask to explain and discuss the stakes involved in the decision. Understanding the stakes can help students to balance trade-offs when conflicting proposals are considered. This exchange of arguments is important for learning, and can change student's perspectives. When all students are asked to explain their stake in the decision, an immense information overload would occur (Noam, 2005). To aggregate information about stakes, groups can create joint proposals, or discuss proposals offered by individuals. In order to support this process a technique for convergence is required.

If a more participative and direct democratic system is required, the students can be asked, not only to indicate the effect of proposals, but also to initiate or contribute to the actual design of the proposal. In this case students in the democratic exercise are asked to develop proposals. Again, strong aggregation is required to avoid the evaluation of infinite amounts of proposals. A way to do this is 'bureaucracy' when submitting a proposal is cumbersome, and requires a lot of paperwork, less proposals will be submitted. However, in a direct democracy, participation is valued, and technology should enable simplification of the submission of proposals. To enable everyone to submit, while avoiding information overload, the toolbox offers suggestions for technology that supports convergence and refinement of proposals while enabling everyone to submit a proposal. To further decide on proposals, and to refine them to achieve consensus among stakeholders, similar techniques are discussed above can be used, with one difference; the techniques should contain decision rules, to actually indicate the 'winning' proposal as the outcome of the decision.

With this overview we can sketch the requirements for a facilitation toolbox for stronger e-democracy. To offer a first draft of a toolbox with these methods, we need a format for the methods. For this purpose we will use the design pattern concept; and specifically thinkLets, which are design patterns for collaboration support.

\section{The design pattern concept}

Design patterns are combinations of a recurring problem and reusable solution description. The original pattern concept described by Alexander (Alexander, 1979) has been widely adopted in the software engineering world after introduction by the gang of four (Gamma et al., 1995). In Alexander's words: "a pattern describes a problem which occurs over and over again and then describes the core of the solution to that problem, in such a way that you can use this solution a million times over, without ever doing it the same way twice (p. x, Alexander et al., 1977)".

Patterns were originally intended by Alexander (1979) to support teaching, capturing, and sharing expert knowledge. They can be used to teach practitioners and novices, but they will also offer a valuable library for experts. We like to see pattern languages as living documents that further develop in a design community. The use of design patterns 
does not only affect the efficiency of the design effort, it also improves the learning efficiency of novices (in this case teachers) to understand the principles behind the methods (Kolfschoten et al., 2010).

Design patterns for collaboration are called thinkLets (Kolfschoten et al., 2004a,b, 2006; de Vreede, Briggs, \& Kolfschoten, 2006). A thinkLet, in essence exists of a set of rules that are invoked on participants as a method to facilitate the creation of a specific pattern of collaboration with a specific result. The rules specify what participants should do, under which constraints and with the use of which capabilities. Rules can be instantiated with different content-parameters and with different tools; the tools and configurations instantiate the capabilities to execute the actions and the parameters instantiate the constraints on the actions.

Input-parameters: Input-parameters are the content specific variables in the thinkLet. Constraining parameters are the variables that need to be instantiate to specify the constraints to the actions described in the rules. Such parameters can indicate a type of input or a criterion for voting.

Capabilities: the capabilities required are specified in terms of requirements and rights. Requirements can be an (electronic) page, an input device, a discriminator etc. rights can be rights to view, modify, move, etc. These capabilities can then be instantiated using software.

\section{A toolbox for facilitation of e-democracy}

To specify the e-democracy methods we will describe the rules and capabilities that can be used to achieve the requirements in the methods. We will present four key design patterns for a stronger e-democracy:

- Individual student proposal gathering.

- Student Group proposal gathering.

- Consensus building based on voting.

- Consensus and compromise building.

\subsection{Individual student proposal gathering}

In this method students submit proposals. If each student submits a proposal information overload will quickly emerge. To avoid this several constraints can be added.

In this method, the requirements to a proposal are strict in order to limit the number of proposals. This forces students to consider different aspects of a proposal, which will lead to more detailed proposals, that are well reasoned. Requirements can be that certain details of the proposal are specified, or that the submitter makes an argument on why his/her proposal meets a specific criterion. For this a submission form can be used. Strict requirements raise the barrier to submit, therewith reducing the amount of proposals. 
However, it also discourages students with less developed ideas to participate. To reduce the number of proposals without requirements to the content of the proposal, a rule can be that only unique proposals can be submitted. In such system, a proposal can be submitted only when the author can argue its uniqueness. Alternatively, a facilitator can identify similar proposals and propose students to merge their proposals instead.

When a proposal is already in the list, students can indicate their preference. In this way each student can either offer a new proposal or vote for another proposal. Many social network sites now offer tools to 'like' 'unlike' and rate contributions or proposals online (e.g. facebook). Algorithms for the automatic analysis of double proposals are being developed based on ontology's. When students can not only like a proposal, but also give feedback or suggestions to improve the proposal, an improvement cycle can be made. The original submitter of the proposal can revise his proposal based on these comments. This will reduce the number of similar proposals. Facilitation is required to stimulate students that submit proposals to also revise these. A wiki offers support for such process.

An example of this process is offered on the website (Greenapple, 2011) of the green apple school initiative. Here you can find an example of this approach. Schools can submit a green idea, look at proposed projects of others and share recommendations and comments on the project proposals though various social networking sites. When submitting a project a form with several required fields is offered to ensure a complete project submission. An example of this is a school project in Wales, UK, where pupils were asked to come up with proposals to improve the environment around the school, and lobby for their proposals at the local council (Elias, 2011). Also, requests for proposals are often found in the context of proposals for the reduction of the universities carbon footprint and sustainability. An example of this is the Hooper sustainability award at Northern Arizona University (Hooper Sustainability Award, 2011); the requirements to submit a proposal are extensive, and students have to seek support from a professor. A tool that supports this process is google moderator, that offers tools to collect suggestions from a large public (Google moderator, 2011).

Rules and Capabilities:

- Each student can submit a proposal to a collective page (you can offer different ways of submitting the proposal like video, text or pictures).

- All proposals are treated equally.

- The method for decision making about the proposals and the criteria involved are explained and transparent.

- Only proposals that meet requirements (note: not criteria) will be taken into account, students have to submit a full and complete proposal.

- All students can view the proposals that are submitted.

- All students can propose alternations/comments to a proposal.

- Only the original submitter of a proposal can alter his/her proposal. 


\subsection{Student group proposal gathering}

To reduce the amount of proposals a minimum number of students to jointly submit a proposal, or you can require a minimum amount of supporters for the proposal to be considered. In some occasions it would be nice for a school to collect proposals from students to understand different perspectives and stakes involved in the decision. For this purpose groups can form to create proposals from a specific perspective. Each group is represented by a Stakeholder representative, who can post an initial proposal. Followers should discuss the proposal, and they should be able to offer alternatives. A summary of each group's arguments is updated with regular intervals to create overview. Being a stakeholder representative thus takes extra effort and should be awarded in some way. It might also be useful to make a small group responsible for the task of stakeholder representative to avoid that people affiliate with a popular representative rather than with his/her stakes. Another solution is to make the representative anonymous. Anonymity of stakeholder representatives and supporter can also reduce the barriers to participate for students that represent minority ideas. Furthermore, it offers some level of safety for students to change their opinion.

In some countries there are youth councils in which youth develops policies to address critical youth problems such as poverty, unemployment and education (Silbernagl, 1996). Many Schools also have student councils for which the members are elected. Also, some schools encourage a student voice in school reform plans, and such involvement is stimulated by e.g. SoundOut, an organization that stimulates and supports student voice in reform (SoundOut, 2011). Gathering stakes can be performed by creating discussions on interest groups chaired by stakeholder representatives. Such groups can be created on social network sites such as facebook or linked-in, but also in e.g. blackboard or sharepoint.

Rules and Capabilities:

- The proposal that is offered for response is explained to the students by an impartial party.

- Students can become stakeholder representative, other students can support them.

- Stakeholder representatives can write a summary of the arguments and position of the stakeholders, followers can give comments for improvement.

- The stakeholder representatives have to update their response based on comments to mature their arguments and after several cycles submit them.

- Anonymity can be used to reduce barriers for the contribution of minority stakes.

\subsection{Consensus building based on voting}

This method is based on the Crowbar thinkLet (Briggs \& de Vreede, 2001). In this method one or more proposals are presented to the students, preferably with a good explanation of its implications and pro's and con's so students can make an informed 
(strong) choice. It is important that the explanation is made by an impartial party with sufficient expertise to avoid bias. While students will decide based on discussion, it can help them to first gather votes to inform their joint decision. Voting should be anonymous, so there is psychological safety for students with a minority perspective. If there is only one proposal, a logic voting method would be to let people vote "yes or no". When there are multiple proposals we can let students select a favorite and for the others choose 'against', or 'neutral', or rank proposals. Note that ranking becomes more difficult when there are many proposals (e.g. more than 10). To get a more detailed score, it is also possible to rate proposals on one or more criteria, and to use a qualitative scale (very successful, successful, average, not successful, very unsuccessful). Voting alone does not engage students in explaining different perspectives. Therefore it can be useful to vote in several rounds. This gives students insights in the consequences of their votes, and encourages debate, in which students can sharpen or change their perspective. When engaging in a debate about voting results, it is interesting to show students the spread in their votes, and discuss reasons to score a proposal high or low. When facilitating such discussion it is important to guard that students are not forced to reveal how they voted. However, one can ask a student general reasons high or low votes, or an explanation of differences in the scores.

For a quick approach, voting or ranking is used to calculate a majority vote; the one that is selected as favorite by most students. Alternatively, for compromise; the one ranked highest when favorite and neutral are counted and favorite has a higher weight factor. Third, it is possible to go for a 'closest to consensus' decision rule; the one with the least 'against' votes (e.g., Balthazard, Ferrell, \& Aguilar, 1998; Cheng \& Deek, 2007; Gavish \& Gerdes, 1997; Levin \& Nalebuff, 1995). Again the method for decision making should be explained to the students on beforehand, and results should be reported in a transparent way. A key pitfall in voting is that the outcome is difficult to disregard. It is important to consider this on beforehand.

An example is the best teacher award that is organized by many schools. In the discussion on the innovative educator different voting approaches are discussed (Educator, 2011), particularly deliberating the differences of a complex evaluation system versus a simple transparent preference system. In some schools, teacher evaluations are used in the decision to hire a teacher for a next year. An example of this is the Sudbury school model (The Sudburyschool, 2011) where weekly school meetings are held to determine and maintain rules and budgets to resolve issues, and to hire or fire staff. Such highly democratic models require thorough thinking of the decision making model in voting and the choice between consensus or majority voting (The Booroobin School, 2000).

Rules and Capabilities:

- Proposals are explained to the students by an 'impartial party'.

- Students vote anonymously.

- Students can rate proposals in a way that enables them to state both preference and acceptance of proposals. 
- The method for decision making about the proposals and the criteria involved are explained clearly.

- 2-3 rounds are used to enable students to consider the implications of their vote, and to change their minds.

- Debate and exchange of arguments and implications is stimulated between the voting rounds based on an analysis of the spreading in the voting results.

\subsection{Consensus and compromise building}

To build consensus or to create a compromise, a full scale discussion will be very difficult. However, representatives of stakeholders could try to find a compromise or consensus solution and offer it to the students for voting or to gather stakes. To build consensus on a proposal or to find a compromise, four levels of disagreement need to be overcome; differences of meaning, differences of information, differences of mental models and conflicting stakes (Briggs, Kolfschoten, \& de Vreede, 2005). Disagreements on the lower levels need to be resolved in order to be able to have an efficient and effective discussion on the fundamental disagreement. For this, students need to see different perspectives. This is achieved by asking people to argue in favor of the view-points of others and against their own. A technique to accomplish this is the point-counter-point thinkLet (Briggs \& de Vreede, 2001). This process needs to be structured, and it will in some cases take some convincing to let go of one's own opinion and instead argue from a different perspective. However, this is a critical skill and also helps in the end to strengthen one's own arguments. In this approach, students formulate propositions on how to address a particular problem. The students then go through an arguing phase in which they have to reflect on the propositions of other students from a given perspective. Once arguments are collected in several iterations, the students are asked to propose compromises, that they again revise based on feedback. The resulting compromises can be put to a vote.

Consensus building is often considered a skill that students should learn. Teaching materials to train children in consensus building are available, and often include small games or teambuilding games. To support consensus building and creating shared understanding over multiple perspectives, it is critical to offer students guidance to stimulate them to think of a problem from different perspectives. For this a chat or discussion forum could be used, but the teacher needs to be involved in the discussion to play the devil's advocate role, and to stimulate thinking about the problem from different perspectives. Also the use of propositions can help here. A discussion forum, e.g. available on blackboard and in most social software platforms, will support the discussion of multiple propositions.

Rules and Capabilities:

- Small groups of students have to jointly develop a proposition on the problem, a proposal on how to deal with it. If you have too many groups, you can merge the proposals of groups that are similar to reduce it to 10-20 proposals. 
- The proposals are divided in such way that students do not get to argue about their own proposition.

- Students are asked to give the best argument they can think of in favor of the proposition in front of them (again, they can formulate these in small groups to reduce the amounts of arguments).

- They now move to a next proposal and need to give the best argument the can think of against the proposal, these steps are repeated, till all proposals have several arguments in favor and against. Instead of arguing in favor or against, you can also let them argue from different stakeholder perspectives.

- After several rounds, depending on the group size and time available, stakeholders are asked to propose a compromise for the opposing arguments.

- In several rounds students are asked to improve the compromises proposed.

\section{Conclusions and further research}

The techniques presented here can support different democratic activities, and offer examples of how they can be used in education. While facilitating them in education can be challenging, carefully implementation can create meaningful debates and will teach students critical multi perspective thinking skills. Based on the techniques above we can summarize the following guidelines:

- There can be high social barriers for students to represent minority ideas, and to think in 'the enemy's perspective'. Facilitation of this process is important, and sometime anonymity is required to ensure a focus on arguments, and offer psychological safety.

- Democracy is different from traditional teaching, and implications of adopting a democratic approach should be carefully considered.

- Thinking from multiple perspectives requires high cognitive load, and often it is necessary to let go of one's own perspective to be able to understand a different perspective. This can be difficult and somewhat scary, and requires some level of self-confidence.

- Changing perspectives after you strongly argued for one, can mean that students feel they lose face. Again psychological safety should be facilitated to enable students to learn and change their mind.

- Focus on debate, creating shared understanding and empathy for different perspectives. This is the most important for learning. However, once such process has started, students will want to see an outcome. Working in cycles and small groups further encourages reflection.

- Ensure a fair process where rules are clear in advance. Make sure that results are transparent, and that those that guard the process are trusted and considered fair. 
- Use strict requirements for new contributions to ensure that proposals and arguments are complete, so they can be carefully considered by others. You can use small groups and several rounds to develop contributions.

- Let students do their own improvement cycles to divide the workload and ensure internal debate to sharpen perspectives.

- Use several rounds of decision making to show students implications of choice and to create understanding and time to change opinion.

The guidelines and patterns described here can be used as a basis to implement e-democracy in education. They offer a basis for design and include guidelines on how to deal with the pitfalls of e-democracy, and they are adaptable to the broad variety of circumstances in which e-democracy can be used in education.

When looking for the examples cited in this paper it became clear that tools and methods to support e-democracy are not widely available. More research is required to develop such techniques and tools, and to develop teaching materials to transfer them to education practices. Further, more understanding of the skills and learning goals related to e-democracy in different contexts is required.

\section{Acknowledgements}

The author would like to thank Professor Simon French and Professor Linda Macaulay for their support in this research direction.

\section{References}

Alexander, C. (1979). The Timeless Way of Building. New York: Oxford University Press.

Alexander, C., Ishikawa, S., Silverstein, M., Jacobson, M., Fiksdahl-King, I., \& Angel, S. (1977). A Pattern Language, Towns, Buildings, Construction. New York: Oxford University Press.

Astrom, J. (2001). Should Democracy Online be Quick, Strong or Thin. Communications of the ACM, 44(1), 49-51.

Balthazard, P., Ferrell, W. R., \& Aguilar, D. L. (1998). Influence Allocation Methods in Group Decision Support Systems. Group Decision and Negotiation, 7(4), 347-362.

Bostrom, R. P., Watson, R. T., \& Kinney, S. T. (Eds.). (1992). Computer Augmented Teamwork, A Guided Tour. New York: Van Nostrand Reinhold.

Briggs, R. O., Kolfschoten, G. L., \& de Vreede, G. J. (2005). Toward a Theoretical Model of Consensus Building. Paper presented at the Americas Conference on Information Systems, Omaha.

Briggs, R. O., \& de Vreede, G. J. (2001). ThinkLets, Building Blocks for Concerted Collaboration. Delft: Delft University of Technology.

Carr, W., \& Hartnett, A. (1996). Education and the Struggle for Democracy. The politics of educational ideas. Buckingham: Open University Press.

Cheng, K. E., \& Deek, F. P. (2007). A Framework for Studying Voting in Group Support Systems. Paper presented at the Hawaii International Conference on System Sciences, Waikoloa.

Clawson, V. K., Bostrom, R., \& Anson, R. (1993). The Role of the Facilitator in Computer-Supported Meetings. Small Group Research, 24(4), 547-565.

Clift, S. (2000). An Internet of Democracy. Communications of the ACM, 43(11), 31-32. 
de Vreede, G. J., Boonstra, J., \& Niederman, F. A. (2002). What is Effective GSS Facilitation? A Qualitative Inquiry into Participants' Perceptions. Paper presented at the Hawaii International Conference on System Science.

de Vreede, G. J., Briggs, R. O., \& Kolfschoten, G. L. (2006). ThinkLets: A Pattern Language for Facilitated and Practitioner-Guided Collaboration Processes. International Journal of Computer Applications in Technology, 25(2/3), 140-154.

de Vreede, G. J., Vogel, D. R., Kolfschoten, G. L., \& Wien, J. S. (2003). Fifteen Years of in-situ GSS Use: A Comparison Across Time and National Boundaries. Paper presented at the Hawaii International Conference on System Science, Los Alamitos.

den Hengst, M., \& Adkins, M. (2007). Which collaboration patterns are most challenging: A global survey of facilitators. Paper presented at the Hawaii International Conference on System Science, Waikoloa.

den Hengst, M., Adkins, M., van Keeken, S. J., \& Lim, A. S. C. (2005). Which facilitation functions are most challenging: A global survey of facilitators. Paper presented at the Group Decision and Negociation conference, Vienna.

Dennis, A. R., \& Wixom, B. H. (2002). Investigating the Moderators of the Group Support Systems Use with Meta-Analysis. Journal of Management Information Systems, 18(3), 235-257.

Dewey, J. (1916). Democracy and Education. New York: The Free Press.

Dillenbourg, P. (1999). What do you Mean by 'Collaborative Learning'? In P. Dillenbourg (Ed.), Collaborative-Learning: Cognitive and Computational Approaches (pp. 1-19). Oxford: Elsevier.

Educator, T. I. (2011). The Best Teacher Evaluation System I've Heard of!. Retrieved 26-4-2011, from http://theinnovativeeducator.blogspot.com/2011/01/best-teacher-evaluation-system-ive.html

Elias, L. (2011). Cwmbach Junior School pupils lobby council for village improvements.

Entin, E. B., Sidman, J., \& Neal Gualtieri, L. (2009). Computer-Supported Collaborative Learning: Best Practices and Principles for Instructors: Development of online distributed training: Practical considerations and lessons learned. eLearn, 2009(9).

Faieta, B., Huberman, B., \& Verhaeghe, P. (2006). Scalable Online Discussions as Listening Technology. Paper presented at the Hawaii International Conference on System Sciences, Kauai.

Felsenthal, D. S., Maoz, Z., \& Rapoport, A. (1993). An Empirical Evaluation of Six Voting Procedures: Do They Really Make Any Difference? British Journal of Political Science, 23(1), 1-27.

Fjermestad, J., \& Hiltz, S. R. (2001). A Descriptive Evaluation of Group Support Systems Case and Field Studies. Journal of Management Information Systems, 17(3), 115-159.

Forrester (2011). Social technology growth. Retrieved 20-3-2011, 2011, from http://forrester.typepad.com/ groundswell/2009/08/social-technology-growth-marches-on-in-2009-led-by-social-network-sites.html

Gamma, E., Helm, R., Johnson, R., \& Vlissides, J. (1995). Elements of Reusable Object-Oriented Software. Reading: Addison-Wesley.

Gavish, B., \& Gerdes, J. H. (1997). Voting Mechanisms and Their Implications in a GDSS Environment. Annals of Operation Research, 71(1), 41-74.

Greenapple (2011). Retrieved 3-20-2011, from http://www.greenapplegrants.ca/submit-your-idea/index.en. html

Gronlund, A. (2003). E-Democracy: In Search of Tools and Methods for Effective Participation. Journal of Multi-Criteria Decision Analysis, 12, 93-100.

Hayne, S. C. (1999). The Facilitator's Perspective on Meetings and Implications for Group Support Systems Design. DataBase, 30(3-4), 72-91.

Helquist, J. H., Kruse, J., \& Adkins, M. (2006). Group support systems for very large groups: A peer review process to filter brainstorming input. Paper presented at the Americas Conference on Information Systems, Acapulco, Mexico.

Hooper Sustainability Award (2011). Hooper Sustainability Award. Retrieved from http://www.research. nau.edu/undergraduate/hooper.aspx 
Ivaldi, G. (2006). Beyond France's 2005 referendum on the European constitutional treaty: Second-order model, anti-establishment attitudes and the end of the alternative European utopia. West European Politics, 29(1), 47-69.

Johnson, D. W., \& Johnson, R. T. (1994). Learning Together and Alone. Needham Heights: Allyn and Bacon.

Kolfschoten, G. L., Appelman, J. H., Briggs, R. O., \& de Vreede, G. J. (2004a). Recurring Patterns of Facilitation Interventions in GSS Sessions. Paper presented at the Hawaii International Conference on System Sciences, Los Alamitos.

Kolfschoten, G. L., Briggs, R. O., Appelman, J. H., \& de Vreede, G. J. (2004b). ThinkLets as Building Blocks for Collaboration Processes: A Further Conceptualization. Paper presented at the CRIWG, San Carlos, Costa Rica.

Kolfschoten, G. L., Briggs, R. O., de Vreede, G. J., Jacobs, P. H. M., \& Appelman, J. H. (2006). Conceptual Foundation of the ThinkLet Concept for Collaboration Engineering. International Journal of Human Computer Science, 64(7), 611-621.

Kolfschoten, G. L., Lukosch, S. G., Verbraeck, A., Valentin, E., \& de Vreede, G. J. (2010). Cognitive Learning Efficiency Through the Use of Design Patterns in Teaching. Computers and Education, 54(3), $652-660$.

Larson, A. (2006). Global Survey 2006: Middle East Progress Amid Global Gains in Freedom. 2006, from www.freedomhouse.org

Levin, J., \& Nalebuff, B. (1995). An Introduction to Vote-Counting Schemes. Journal of Economic Perspectives, 9(1), 3-26.

Macaulay, L. A., Alabdulkarim, A., \& Kolfschoten, G. L. (2006). An analysis of the role of the facilitator and alternative scenarios for collaboration support. Paper presented at the First HICSS Symposium on Case and Field Studies of Collaboration, Kauai.

McQuaid, M. J., Briggs, R. O., Gillman, D., Hauck, R., Lin, C., Mittleman, D. D., et al. (2000). Tools for Distributed Facilitation. Paper presented at the Hawaii International Conference on System Science, Waikoloa.

Mittleman, D. D., Briggs, R. O., Nunamaker, J. F., Jr., \& Romano, N. C., Jr. (1999). Lessons Learned from Synchronous Distributed GSS Sessions: Action Research at the US. Navy Third Fleet. Paper presented at the The 10th EuroGDSS Workshop, Copenhagen, Denmark.

Google moderator (2011). Retrieved 3-20-2011, 2011, from https://www.google.com/moderator/\#0

Niederman, F., Beise, C. M., \& Beranek, P. M. (1993). Facilitation Issues in Distributed Group Support Systems. Paper presented at the Conference on Computer personnel research, St. Louis.

Nielsen (2011). Social media accounts. Retrieved 22-3-2011, 2011, from http://blog.nielsen.com/ nielsenwire/online_mobile/social-media-accounts-for-22-percent-of-time-online/

Noam, E. M. (2005). Why the Internet Is Bad for Democracy. Communications of the ACM, 48(10), 57-58.

Nunamaker, J. F. J., Briggs, R. O., Mittleman, D. D., Vogel, D., \& Balthazard, P. A. (1997). Lessons from a Dozen Years of Group Support Systems Research: A Discussion of Lab and Field Findings. Journal of Management Information Systems, 13(3), 163-207.

Reinig, B. A., Briggs, R. O., \& Nunamaker, J. F. (1998). Flaming in the Electronic Classroom. Journal of Management Information Systems, 14(3), 45-60.

Romano, J. N. C., Nunamaker, J. J. F., Briggs, R. O., \& Mittleman, D. D. (1999). Distributed GSS Facilitation and Participation: Field Action Research. Paper presented at the Hawaii International Conference on System Sciences, Los Alamitos.

Schwarz, R. M. (1994). The Skilled Facilitator. San Francisco: Jossey-Bass Publishers.

Silbernagl, T. (1996). Establishment of Structures for Youth Participation \& Youth Promotion. Retrieved from http://www2.gtz.de/dokumente/bib-2010/gtz2010-3224en-youth-structures.pdf

Smith, M. K. (2001). Education for democracy. Retrieved 22-3-2011, 2011, from http://www.infed.org/ biblio/b-dem.htm

SoundOut (2011). SoundOut Student Voice in School. 
Ter Bush, R., \& Mittleman, D. D. (2006). Silence, Attribution Accuracy and Virtual Environments: Implications for developers and facilitators. Paper presented at the Hawaii International Conference on System Sciences, Kauai.

The Booroobin School (2000). DSM: Re: Majority Rule vs. Consensus. Retrieved from http://www.sudval. org/archives/dsm4/0032.html

The Sudburyschool (2011). How the School is Governed.

Veen, W. (2009). Homo Zappiens. Amsterdam: Pearson Education Uitgeverij.

Wilson, J., \& Jessup, L. M. (1995). A Field Experiment on GSS Anonymity and group member status. Paper presented at the Hawaii International Conference on System Science, Waikoloa.

Young, P. (1995). Optimal Voting Rules. The Journal of Economic Perspectives, 9(1), 51-64. 